\title{
The simple macroeconomics of fiscal austerity: Public debt, deficits and deficit caps
}

\author{
Thomas I. Palley*
}

\begin{abstract}
This paper explores the macroeconomics of fiscal austerity. A binding budget deficit cap makes the economy more volatile by turning the government budget into an automatic destabilizer. Public debt helps maintain aggregate demand $\mathrm{AD}$ in the presence of a lower price level because a lower price level increases the real value of public interest payments and also has a positive wealth effect. That makes public debt significantly different from private debt. If the economy is subject to a binding deficit cap public debt may no longer stabilize output. This is because increased real interest payments may be matched by spending cuts, giving rise to a negative balanced budget multiplier.
\end{abstract}

JEL classifications: EI2, E60, E62, H62

Keywords: fiscal austerity, budget deficit cap, public debt, lower price level

\section{Introduction}

The past two years has seen much attention focused on the issue of private sector debt. Private sector over-leveraging and disregard of risk by borrowers and lenders are widely viewed as being critical ingredients in the making of the Great Recession of 2007-2009.

Now, there are indications the economic crisis has moved to a second stage in which excessive public sector debt becomes the perceived problem. Many governments have engaged in bond financed expansionary fiscal policy and financial sector bailouts, which has created large deficits and increased public sector debt. Consequently, concern with public debt is driving an agenda of fiscal austerity that includes proposals for cutting government spending and strengthening rules that limit budget deficits as a share of GDP.

* New America Foundation, Washington DC.

Correspondence Address:

Thomas I. Palley, I913 S Street NW, Washington, DC 20009, USA, e-mail: mail@thomaspalley.com.

Received 26 January 20II, accepted I4 July 20II

C) INTERVENTION 9 (I), 20I2, 9I-IO7 
The current paper examines the macroeconomics of fiscal austerity using a Keynesian income-expenditure framework with pure bond financing. The paper provides another example of the analytical power of the income-expenditure model, showing how fiscal austerity works and why it is likely to be counter-productive. Deficit ceilings are especially problematic as they prevent the budget deficit from performing its automatic stabilizer role and turn the deficit into an automatic destabilizer. The analysis that is developed is particularly germane to Europe where countries are constrained to pure bond financing because they no longer have their own central banks, and where policymakers are pursuing fiscal austerity in a framework of budget deficit caps. ${ }^{\mathrm{I}}$

The paper also focuses on two aspects of public sector debt that have received inadequate attention and make public sector debt completely different from private sector debt. The first is the demand effects of interest payments on the public debt. Unlike private sector interest payments (Palley 1994), public sector interest payments increase aggregate demand. The second aspect concerns price level effects of public debt. Unlike private debt, public debt has a positive impact on aggregate demand in the presence of a lower price level.

Finally, the paper makes clear the need to take account of the government budget constraint. Analysis that takes no account of this constraint implicitly assumes that government is financially unconstrained. If government is financially constrained, this fundamentally changes outcomes.

\section{The model economy}

The economy is described in terms of a Keynes-Kalecki income-expenditure model. The Keynesian dimension is demand determined equilibrium. The Kaleckian dimension is aggregate demand depends on the functional distribution of income.

The production and pricing side of the economy is as follows

$$
\begin{aligned}
& Y=a N \quad a>0, \\
& p=[1+z] w / a \quad z>0, \\
& \omega=w / p=a /[1+z], \\
& Y=E,
\end{aligned}
$$

$Y=$ real output, $a$ = average product of labor, $N=$ employment, $p=$ price level, $z=$ firms' mark-up, $w=$ nominal wage, $\omega=$ real wage, and $E=$ real aggregate demand. Equation (1) is a linear production function. Equation (2) is the pricing rule whereby firms set prices

I The European Central Bank (ECB) has been helping Greece by buying Greek bonds, which means it is implicitly helping finance the Greek budget deficit. However, that help has been sporadic and most eurozone fiscal authorities are operating without financing assistance from the ECB. 
as a mark-up over unit labor costs. Equation (3) determines the real wage. Equation (4) is firms' production rule under which firms produce to demand.

National income, aggregate demand and government finances are as follows:

$$
\begin{aligned}
& Y=C+S+T, \\
& E=C+I+G, \\
& C=\beta\left[1-t_{W}\right] W+\alpha\left[1-t_{\Pi}\right]\{\Pi+i D / p\}+\gamma D / p \quad 1>\beta>\alpha>\gamma>0, \\
& W=\theta Y \quad 0<\theta<1, \\
& \Pi=[1-\theta] Y, \\
& B=T-G, \\
& T=t_{W} W+t_{\Pi}[\Pi+i D / p]-i D / p .
\end{aligned}
$$

All variables except for public debt $(D)$ are in real terms. $C=$ consumption spending, $S=$ aggregate saving, $T=$ total tax revenues, $I=$ investment spending, $G=$ government spending, $\beta$ = propensity to consume out of wage income, $\alpha$ = propensity to consume out of profit and interest income, $\gamma=$ propensity to consume government bond wealth, $t_{W}=$ tax rate on wage income, $t_{\Pi}=$ tax rate on profit and interest income, $\theta=$ wage share of national income, $W=$ real wage bill, $\Pi=$ real profit income, $i=$ nominal interest rate, $D=$ public sector nominal debt, and $B=$ budget deficit.

Equation (5) is the definition of national income. Equation (6) is the definition of $A D$ in a closed economy. Equation (7) determines aggregate consumption. It embodies a Kaleckian structure in that the propensity to consume out of after-tax wage income $(\beta)$ is greater than propensity to consume out of after-tax profit and interest income $(\alpha)$. It also includes a consumption wealth effect $(\gamma)$ from government bonds. The microeconomic rationale for the different aggregate consumption effects of wage and profit income is that profit income accrues disproportionately to well-off households who have a lower propensity to consume (Palley 20IO). Investment and government spending are exogenously determined.

Equation (8) determines the wage share, while equation (9) determines the profit share. Equations (10) and (11) determine the condition of government finances. Equation (10) is the government budget constraint which defines the budget deficit or surplus. Equation (11) determines total tax revenues which consist of taxes on wages, profits and interest income, less interest payments on the public debt that are a transfer payment. ${ }^{2}$

2 In the general public's mind transfers (including interest payments) are identified with government spending. However, from an economic standpoint transfers constitute outlays and are not government expenditures $(G)$ which refer to purchases of goods and services. In effect, transfers are negative taxes. An alternative specification that distinguishes between government purchases and transfers would be $B=T-G-O$ where $O=i D / p$. 
Using equations (4), (5) and (6) yields the goods market equilibrium condition

$$
I-S=T-G \text {. }
$$

This is a restatement of the familiar Keynesian condition that leakages out of the circular flow of income equal injections. The left hand side of equation (12) is a measure of private sector net saving; the right hand side is a measure of public sector saving. This relationship between aggregate net private saving and aggregate public saving was emphasized long ago by Tobin (1963). For every lender (saver) there must be a borrower (dis-saver). If the private sector wants to run a net surplus (i.e. $S>I$ ), the public sector must run a deficit (i.e. $G>T$ ). Correspondingly, if the private sector wants to invest more than it saves $(I>S)$, the public sector must run a surplus $(T>G)$ and lend to the private sector. It does so by redeeming public debt. This relationship has also been emphasized by Godley and Zezza (2006). ${ }^{3}$

Substituting into equation (12) yields

$$
\begin{aligned}
& I-\left[1-t_{W}\right][1-\beta] \theta Y-\left[1-t_{\Pi}\right][1-\alpha][1-\theta] Y+\gamma D / p-\left[1+\alpha t_{\Pi}\right] i D / p \\
& =t_{W} \theta Y+t_{\Pi}[\theta Y+i D / p]-i D / p-G .
\end{aligned}
$$

The two sides of equation (13) are shown in Figure I. Public sector saving is represented by the budget outcome $\left(S_{P U B}=T-G\right)$ which is a positive function of income. Net private sector saving $\left(S_{P R I V}=I-S\right)$ is a negative function of income. The economy is in equilibrium when net private sector saving equals public sector saving. Figure I depicts a situation in which the private sector lends (i.e. has positive net saving) while the public sector borrows (i.e. has a budget deficit and negative net saving), which has been the usual outcome.

\section{Figure I: The relationship between private sector net saving and the public sector balance}

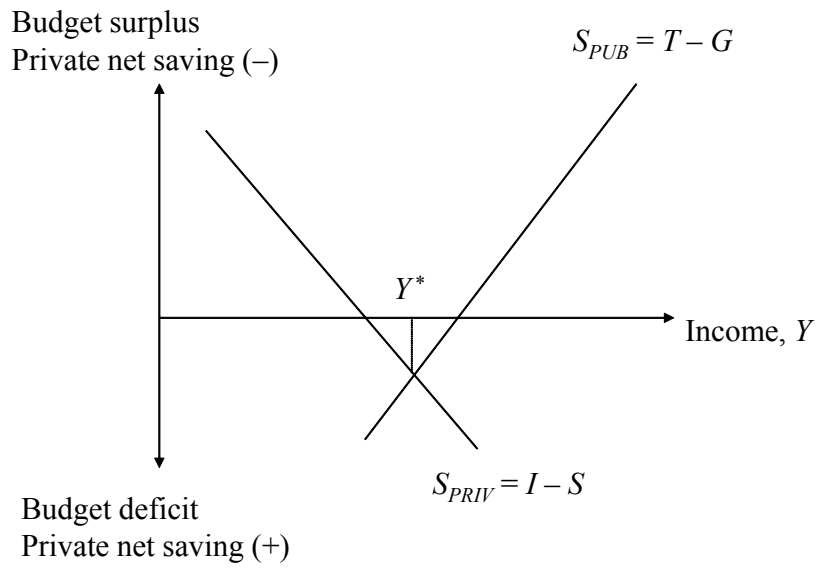

3 In an open economy the trade balance provides an additional vent for private sector saving and $S_{P R I V}=I-S+X-M$. The private sector can increase its saving in the form of exports. 
Recessions can be thought of as shocks to private sector demand that increase private sector net saving. In the current model this is most easily represented as a reduction of investment spending $(I)$ which shifts the $S_{P R I V}$ schedule down, resulting in a new equilibrium with lower income.

The effect on income of a shock to demand depends critically on the slope of the public sector saving schedule $\left(S_{P U B}=T-G\right)$. The flatter this schedule, the larger the fall in income. The slope of the schedule is

$$
d[T-G] / d Y=\zeta=t_{W} \theta+t_{\Pi}[1-\theta]>0 .
$$

The critical parameters are tax rates and the distribution of income. Differentiating with respect to $t_{W}, t_{\Pi}$ and $\theta$ yields

$$
\delta \zeta / \delta t_{W}=\theta>0, \delta \zeta / \delta t_{\Pi}=1-\theta>0, \delta \zeta / \delta \theta=t_{W}-t_{\Pi} \gtrless 0 \text { if } t_{W} \gtrless t_{\Pi} .
$$

Higher tax rates steepen the public sector saving schedule and reduce the impact of private sector demand shocks. This reflects the counter-cyclical automatic stabilizer nature of income taxes. Thus, as $A D$ and income increases in expansions, the tax-take increases thereby limiting the expansion of $A D$ and income. Positive demand shocks that decrease private sector net saving $(I-S)$ are offset by increases in public saving $(T-G)$. The reverse happens in contractions. A system of perfect automatic stabilizers would have the $S_{P U B}$ schedule vertical.

\section{Static debt effects}

Solving the model yields the following expression for the short run equilibrium level of income:

$$
Y=\left\{I+G+\alpha\left[1-t_{\Pi}\right] i D / p+\gamma D / p\right\} / m
$$

where $0<m=\left\{1-\beta\left[1-t_{W}\right] \theta-\alpha\left[1-t_{\Pi}\right][1-\theta]\right\}<1$. Differentiating with respect to nominal debt then yields

$$
d Y / d D=\left\{\alpha\left[1-t_{\Pi}\right] i+\gamma\right\} / p m>0 .
$$

An instantaneous increase (i.e. a helicopter drop) in the level of nominal public debt therefore increases income. The reason is that it increases interest payments on the debt to households, which increases consumption spending and aggregate demand. It also increases household wealth, giving rise to a consumption wealth effect.

The effect of an instantaneous increase in the nominal public debt on the budget outcome is given by

$$
\begin{aligned}
& d[T-G] / d D=\left\{t_{W} \theta+t_{\Pi}[1-\theta]\right\} d Y / d D-\left[t_{\Pi}-1\right] i / p \\
& =\left\{t_{W} \theta+t_{\Pi}[1-\theta]\right\}\left\{\alpha\left[1-t_{\Pi}\right] i+\gamma\right\} / p m-\left[t_{\Pi}-1\right] i / p \gtrless 0 .
\end{aligned}
$$


In principle, this expression is ambiguous. On one hand the increase in debt increases income, which in turn raises tax revenues. On the other hand the increase in debt increases outlays by increasing net interest payments. The expression will tend to be positive, so the deficit falls or surplus increases, the larger the expenditure multiplier $(1 / m)$, the larger the consumption wealth effect $(\gamma)$; and the higher are tax rates $\left(t_{W}, t_{\Pi}\right)$. The last effect reflects the fact that higher tax rates increase tax revenues.

Note, at this stage it has been assumed the government is financially unconstrained. Consequently, the analysis has ignored the budget constraint given by equation (10). Introducing that constraint is key for analyzing the macroeconomics of fiscal austerity.

\section{Price level effects with public debt}

The interaction between the price level and debt has been analyzed extensively with regard to private debt (Fisher 1933, Caskey/Fazarri 1987, Palley I999 and 2008) but the interaction with public debt is less well appreciated. It transpires public debt helps stabilize an economy in the presence of deflation.

To see this consider a situation in which the price level and nominal wages fall proportionately so the real wage is unchanged. Differentiating (14) with respect to the price level $(p)$ yields

$$
d Y / d p=-\left\{\alpha\left[1-t_{\Pi}\right] i+\gamma\right\} D / m p^{2}<0 .
$$

A decrease in the price level increases real output. ${ }^{4}$ The reason is a lower price level increases the real value of interest payments on public debt and increases real wealth, both of which in turn increase aggregate demand and income. Unlike private inside debt, public debt causes a lower price level to have an expansionary effect. ${ }^{5}$

A lower price level also impacts the real budget deficit in surprisingly complicated ways. To understand this effect, consider two cases. The first is when the wealth effect is zero $(\gamma=0)$. The second is when the wealth effect is positive $(\gamma>0)$.

The budget deficit is given by

$$
B=T-G=t_{W} \theta Y+t_{\Pi}\{[1-\theta] Y-i D / p\}-i D / p-G .
$$

Differentiating with respect to $p$ yields

$$
d B / d p=d T / d Y . d Y / d p+i D / p^{2} .
$$

4 The real wage is constant as the nominal wage is assumed to move equi-proportionatel with the price level.

$5 \quad$ A referee pointed out another difference which is that higher private debt imposes an automatic brake on private borrowing that is contractionary, but that does not happen with public debt. 
If there is no wealth effect then $d B / d p>0$ if $1>t_{W}$ and $1>t_{\Pi}$. The proof of this condition is provided in the appendix. ${ }^{6}$ In that case a higher price level pushes the budget toward surplus, while a lower price level contributes to a deficit. The reason is a lower price level increases the real value of interest outlays. Though that stimulates $A D$ and increases tax revenues, the increase in outlays exceeds the induced increase in revenues.

Though this sounds confusing, the logic is simple. In the presence of public debt, a lower price level results in increased real transfer spending and that always increases the budget deficit if the economy is stable. However, part of that increase in real transfers is recouped through higher tax revenues resulting from increased economic activity.

If the wealth effect is positive then the budget deficit, theoretically, may not increase. The reason is the consumption wealth effect from a lower price level is akin to stimulus that comes without a budget cost. The resulting tax revenues from this free stimulus could offset the deficit caused by increased real transfer spending on debt interest payments.

\section{Fiscal austerity: Spending cuts and tax increases}

The above model can be used to analyze fiscal austerity policy. The starting point is the issue of spending cuts versus tax increases, which turns out to be of considerable significance for the stability of austerity policies.

Both spending cuts and tax increases reduce $A D$ and income, but government spending cuts are more contractionary. To see this consider three options: cutting spending by one dollar; raising the wage tax to increase tax revenues by one dollar; and raising the profit tax to increase tax revenues by one dollar.

It can then be shown that the effect on equilibrium output is

$$
\begin{aligned}
& d Y / d G=1 / m>0, \\
& d Y / d t_{w}=-\left\{I+G+\alpha\left[1-t_{\Pi}\right] i D / p+\gamma D / p\right\} \beta \theta / m^{2}<0, \\
& d Y / d t_{\Pi}=-\left\{m \alpha i D / p+\left\{I+G+\alpha\left[1-t_{\Pi}\right] i D / p+\gamma D / p\right\} \alpha[1-\theta]\right\} / m^{2}<0, \\
& m=\left\{1-\beta\left[1-t_{W}\right] \theta-\alpha\left[1-t_{\Pi}\right][1-\theta]\right\} .
\end{aligned}
$$

If $\theta=0.5$ and $D=0$, it can then be shown $\left|d Y / d t_{w}\right|>\left|d Y / d t_{\Pi}\right|$. Raising the tax rate on wage income is more contractionary than raising tax rate on profit income. The logic is richer households have a higher propensity to save and a lower propensity to consume. However,

6 The economic logic of the condition is the same as in the standard income-expenditure model. In that model increased government spending cannot lower the deficit if the tax rate is less than one hundred per cent, and that condition is needed for stability. A similar condition holds in the current model, but now it is that both tax rates must be less than one hundred per cent. If this condition did not hold it would imply government can reduce the budget deficit by increasing real interest payments to the owners of the national debt. 
as debt and the profit share of income increase, raising the tax rate on profit and interest income becomes more contractionary as tax incidence increases because profits and interest constitute a greater share of income.

It can also be shown that if the wage tax rate increases so as to produce one dollar of extra revenue then $|d Y / d G|>\left|d Y / d t_{w}\right|$. The logic is a one dollar reduction in government purchases reduces demand by a full dollar whereas a one dollar increase in wage taxes reduces demand by less than a full dollar because part of that dollar of income was already being saved. The policy implication is that cutting government expenditures is the most contractionary form of fiscal austerity.

Keynesian economic policy logic is therefore doubly at odds with neoliberal policy logic. First, Keynesian logic argues against fiscal austerity in times of demand shortage. Second, Keynesian logic also argues that the worst form of fiscal austerity are measures with large multiplier effects, which makes cutting government spending worst. Neoliberal logic runs counter to both of these Keynesian propositions through its construction of the economic problem as one of saving shortage that constrains investment and causes trade deficits. That construction encourages fiscal austerity to increase government sector saving. It also recommends fiscal austerity should be implemented by cutting government spending first, and wage tax increases are also preferred to profit income tax increases. The reason for this ordering is that taxing profit income has the largest negative effect on private saving, which is to be avoided. The net result is the neoliberal saving shortage hypothesis promotes fiscal austerity, and it also promotes the worst type of regressive fiscal austerity that causes the largest demand contraction.

\section{Fiscal austerity: Budget deficit caps}

A second form of fiscal austerity is via budget deficit caps that limit the deficit as a share of GDP. This proposal can be represented as follows

$$
B=\operatorname{Max}[T-G,-\psi Y] \quad 0<\psi<1,
$$

$B=$ budget deficit or surplus. Equation (16) limits the deficit to a maximum of $\psi Y$. This budget cap is represented in Figure 2 by the negatively sloped ray from the origin and it constrains the actual budget outcome to lie on or above the ray.

Given existing settings for fiscal policy, the budget outcome must lie on the bold faced $\mathrm{V}$-shaped schedule consisting of that part of the budget deficit cap line above the public sector saving schedule and that part of the public sector saving schedule above the budget deficit cap line. When the budget deficit cap is binding the deficit is constrained to lie on the budget deficit cap line.

The analytical significance of a binding deficit cap is it transforms the budget deficit into an automatic destabilizer. The reason is a private sector negative demand shock lowers income and tax revenues, thereby worsening the budget deficit. To satisfy the deficit cap, policy must either increase taxes or lower spending. 
Figure 2: The effect of a budget deficit cap

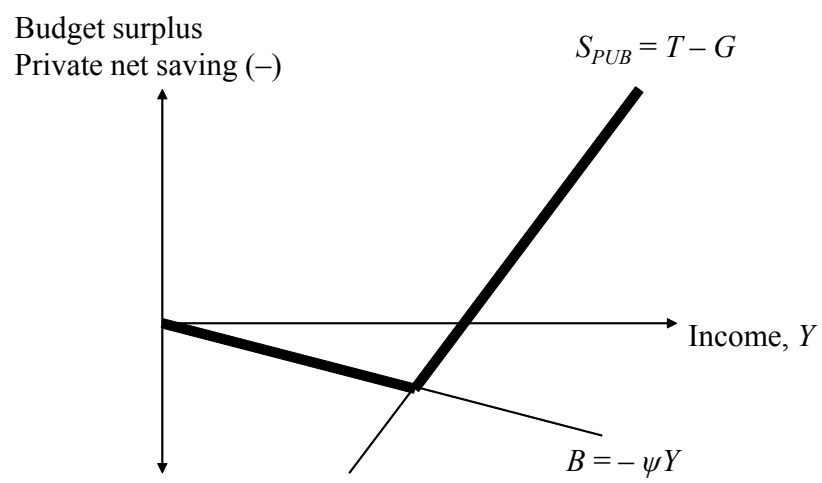

Budget deficit

Private net saving $(+)$

This effect is illustrated in Figure 3. The initial equilibrium is given by the intersection of $S_{P R I V 0}$ and $S_{P U B}$. A negative shock to private investment shifts net private sector saving to $S_{P R I V 1}$ so that it now intersects the budget deficit cap line at $Y_{1}$. Without the cap the new equilibrium would be at the intersection of $S_{P R I V 1}$ and $S_{P U B}$. With the cap the new equilibrium is at the intersection of $S_{P R I V 1}$ and the budget deficit cap line. Because of the deficit cap, policymakers are compelled to raise taxes and lower spending in some combination that shifts the $S_{P U B}$ schedule to the left such that it intersects budget the deficit cap line at $Y_{1}$.

Figure 3: The effect of a negative demand shock in the presence of a binding budget deficit cap

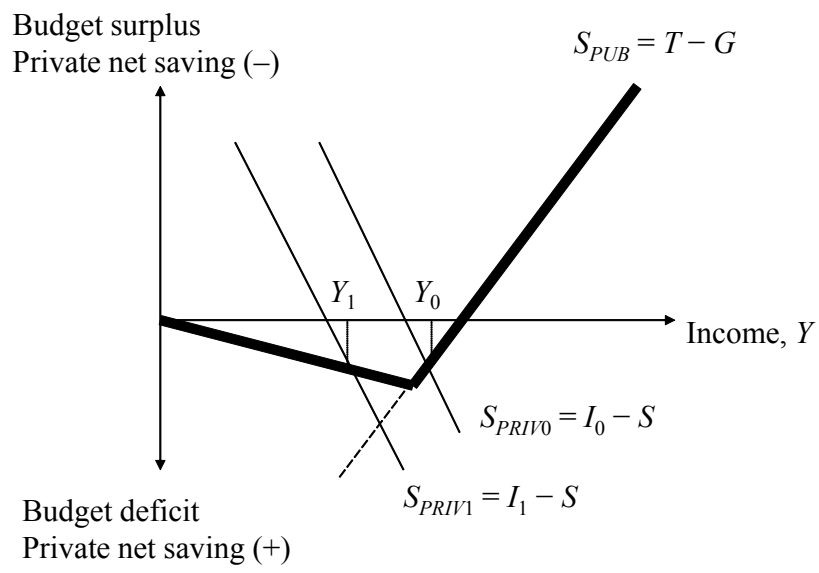


The extent to which the cap acts as an automatic destabilizer depends on the magnitude of the coefficient $\psi$ which represents the deficit-GDP ratio. A smaller ratio makes the cap more binding and flattens the budget deficit constraint in Figure 3. That makes the budget even more pro-cyclical. If no deficit were allowed (e.g. a balanced budget requirement) the public sector saving schedule would correspond to the abscissa.

Analytically, the financially constrained case is given by

$$
\begin{aligned}
& Y=C+I+G, \\
& C=\beta\left[1-t_{W}\right] \theta Y+\alpha\left[1-t_{\Pi}\right]\{[1-\theta] Y+i D / p\}+\gamma D / p, \\
& G=t_{W} \theta Y+t_{\Pi}\{[1-\theta] Y+i D / p\}-i D / p+\psi Y, \\
& B=T-G=-\psi Y .
\end{aligned}
$$

Solving for $Y$ yields

$$
Y=\left\{I+\left[\alpha-\alpha t_{\Pi}+t_{\Pi}\right] i D / p+[\gamma-i] D / p\right\} /\left\{1-\left[\beta-\beta t_{W}+t_{W}\right] \theta-\left[\alpha-\alpha t_{\Pi}+t_{\Pi}\right][1-\theta]-\psi\right\} .
$$

Equation (21) shows that budget deficit caps increase the expenditure multiplier, making the economy more volatile. This can be seen from inspection of the denominator of equation (21) which includes the additional negative terms $t_{W} \theta, t_{\Pi}[1-\theta]$, and $\psi$. The logic is that demand shocks that change $Y$ are amplified because $G$ is tied pro-cyclically to $Y$. A large value of $\psi$ increases the multiplier, making the economy more volatile than a simple balanced budget requirement $(\psi=0)$. However, a high value of $\psi$ also makes it less likely the financial constraint will be binding.

\section{Price level effects in the presence of budget deficit caps}

Section III examined how the presence of public debt impacts the aggregate demand effects of a lower price level assuming government is financially unconstrained. That meant government could increase the real deficit to finance increased real interest payments on the debt. This section examines the effects of a lower price level if government is financially constrained by a budget deficit cap.

In the presence of a budget deficit cap the economy is described by two equations given by

$$
\begin{aligned}
& Y=\left\{I+G+\alpha\left[1-t_{\Pi}\right] i D / p+\gamma D / p\right\} / m, \\
& -\psi Y=t_{W} \theta Y+t_{\Pi}\{[1-\theta] Y+i D / p\}-i D / p-G .
\end{aligned}
$$

Equation (22) determines income and equation (23) is the budget deficit constraint. Earlier, the budget deficit was free to vary so that the two equation system was block recursive. Equation (22) determined the level of income and the budget outcome was determined 
via equation (10). Now, the system is simultaneous and there is an interaction between the budget and the level of income. For instance, if income falls so that tax revenues are down, then government spending must be cut or tax rates increased to satisfy the budget deficit cap.

This last observation makes clear that budget deficit caps also require specifying how the cap is satisfied. For current purposes assume the cap is enforced by adjusting $G$. In this case, the endogenous variables in equations (22) and (23) are $Y$ and $G$. Differentiating equations (22) and (23) with respect to $Y, G$ and $p$, and arranging in matrix form yields

$$
\begin{aligned}
& |1-1 / m||d Y|=\left|-\left\{\alpha\left[1-t_{\Pi}\right] i D / m p^{2}+\gamma D / m p^{2}\right\}\right| d p \\
& \mid\left\{\psi+t_{W} \theta+t_{\Pi}\{[1-\theta]\}-1|| d G||\left\{-\left[1-t_{\Pi}\right] i D / p^{2}\right\} d p \mid .\right.
\end{aligned}
$$

The Jacobian is $|J|=-1+\left\{\psi+t_{W} \theta+t_{\Pi}\{[1-\theta]\} / m \gtrless 0\right.$ if $m \lessgtr\left\{\psi+t_{W} \theta+t_{\Pi}\{[1-\theta]\}\right.$. If $\psi=0.03, t_{W}=0.2, t_{\Pi}=0.4, \theta=0.67$, and $m=0.5$, then $|J|=-0.41$. Given the above parameter values the critical level of $m$ at which $|J|$ changes sign and becomes negative is 0.296. At this critical value the expenditure multiplier $(1 / \mathrm{m})$ is $3.38 .|J|$ is therefore negative for a multiplier less than 3.38 and positive for one greater than 3.38. Most estimates have the multiplier being less than 3.38 and it is therefore assumed $|J|<0$. $^{7}$

The comparative statics for output with respect to the price level are

$$
\begin{aligned}
& d Y / d p=\left\{\left\{\alpha\left[1-t_{\Pi}\right] i D / m p^{2}+\gamma D / m p^{2}\right\}-\left[1-t_{\Pi}\right] i D / m p^{2}\right\} /|J|, \\
& d G / d p= \\
& \quad\left\{\left\{-\left[1-t_{\Pi}\right] i D / p^{2}\right\}+\left\{\alpha\left[1-t_{\Pi}\right] i D / m p^{2}+\gamma D / m p^{2}\right\}\left\{\psi+t_{W} \theta+t_{\Pi}\{[1-\theta]\} / m\right\} /|J| .\right.
\end{aligned}
$$

The numerator of the expression $d Y / d p$ is unambiguously negative if the wealth effect is zero $(\gamma=0)$. Since wealth effects tend to be small, the paper proceeds on this assumption. The numerator of the expression $d G / d p$ is ambiguous. It is more likely to be negative if $m>\left\{\psi+t_{W} \theta+t_{\Pi}\{[1-\theta]\}\right.$ which is consistent with the assumption $|J|<0$.

This yields the tentative results

$$
\begin{aligned}
& d Y / d p \gtrless 0 \text { if } m \gtrless\left\{\psi+t_{W} \theta+t_{\Pi}\{[1-\theta]\},\right. \\
& d G / d p \gtrless 0 \text { if } m \gtrless\left\{\psi+t_{W} \theta+t_{\Pi}\{[1-\theta]\} .\right.
\end{aligned}
$$

A lower price level increases the real value of interest receipts and bond wealth, which increases aggregate demand and output. That would tend to increase output. However, the government is financially constrained by the deficit cap. Given that the lower price level increases the real value of interest, this necessitates a cut in government spending and the

7 The behavior of the system depends on the signing of $|J|$ which is ambiguous. Assigning parameter values can resolve this ambiguity. For this purpose »ballpark« values are assumed. The deficit cap $(\psi)$ is three per cent of GDP; the wage tax rate is twenty per cent; the profit tax rate is forty per cent; the wage share is sixty-seven per cent; and the government expenditure multiplier is two. These values render $|J|$ negative. 
net result is both output and government spending fall. In effect, there is a form of balanced budget multiplier contraction since spending is cut to compensate for the effects of increased real interest payments due to a lower price level. The negative effect of spending cut works directly on aggregate demand, whereas the positive effect of an increase in the real value of interest payments and bond wealth works via the filter of consumption. ${ }^{8}$

This observation links to the earlier discussion of neoliberal political economy. By prioritizing government spending cuts as the way of meeting the budget deficit cap, neoliberal policy maximizes the destabilizing impact of a budget deficit cap. The more general lesson is budget deficit caps are a form of automatic destabilizer, and the extent to which they destabilize depends on whether budget adjustment is via taxes or spending.

\section{Long run stability}

Thus far the paper has considered the short run comparative statics. Initially, the economy was investigated under the assumption the government is financially unconstrained. Thereafter, it was investigated under the assumption that government is financially constrained by a budget deficit cap.

The final issue is long run stability and whether the debt trajectory is stable, defined as tending to a constant debt to income ratio $(D / Y)$. The necessary condition for this is

$$
g_{V}=g_{D}-g_{Y}=0
$$

where $V=D / Y, g_{V}=$ growth of the debt to income ratio, $g_{D}=$ growth of the public debt, and $g_{Y}=$ growth of output. Since the above economy is characterized by zero growth, this condition reduces to $g_{D}=0$.

The growth rate of the public debt is determined by

$$
\mathrm{g}_{D}=B / D=[G-T(Y(D), D)] / D .
$$

This issue was analyzed by Blinder and Solow (1974) for the case of an economy in which government is financially unconstrained. The stability condition is

$$
d \mathrm{~g}_{D} / d D=\left\{-D\left[T_{Y} Y_{D}+T_{D}\right]-[G-T]\right\} / D^{2}<0 .
$$

This condition is satisfied if $T-D\left[T_{Y} Y_{D}+T_{D}\right]-G<0 . Y_{D}>0$ is an important component of this condition as it ensures rising debt generates rising tax revenues that choke off the deficit.

8 As the value of $\psi$ increases this negative effect of higher prices strengthens. The reason is that budget constraint forces the government to be pro-cyclical, and the larger the value of $\psi$ the more procyclical is government policy. An increase in the price level lowers $A D$ and income, which reduces tax revenues. The government must then cut spending proportionately to the reduction of income, with $\psi$ representing the coefficient of proportionality. 
For the current model the financially unconstrained case is given by

$$
\begin{aligned}
& Y=\left\{I+G+\alpha\left[1-t_{\Pi}\right] i D / p+\gamma D / p\right\} / m, \\
& B=G-t_{W} \theta Y-t_{\Pi}\{[1-\theta] Y+i D / p\}+i D / p .
\end{aligned}
$$

Stability again requires $d g_{D} / d D=\left[D B_{D}-B\right] / D^{2}<0$ so that a necessary condition for instability is $B_{D}>0$. Substituting equation (26) into (27) and differentiating with respect to $D$ yields

$$
\begin{aligned}
& \left.d B / d D=B_{D}=-\left\{t_{W} \theta+t_{\Pi}[1-\theta]\right\}\left\{\alpha\left[1-t_{\Pi}\right] i+\gamma\right\} / p m+t_{\Pi} i / p\right\}+i / p \gtrless 0 \\
& \text { if } \left.i \gtrless\left\{t_{W} \theta+\gamma\right\}\left[1-t_{\Pi}-t_{\Pi}[1-\theta]\right\}\left\{\alpha\left[1-t_{\Pi}\right]\right\} / m\right] / m .
\end{aligned}
$$

Figure 4 provides a simple diagrammatic representation of the stable case. If the budget deficit is initially positive $(B / D>0)$ so that the debt is increasing, then the larger debt must bring down the rate of growth of the debt until it converges to zero. When government is financially unconstrained and the interest rate is less than the critical level, the public debt exhibits long run stability. The economic logic is that the budget deficit increases the debt, giving rise to increased bond wealth and increased interest payments that raise aggregate demand and income. This increases tax revenues and reduces the deficit, eventually causing the debt to stop growing. The restriction on the interest rate ensures that induced tax revenues increase faster than debt interest payments.

Figure 4: The case of debt stability

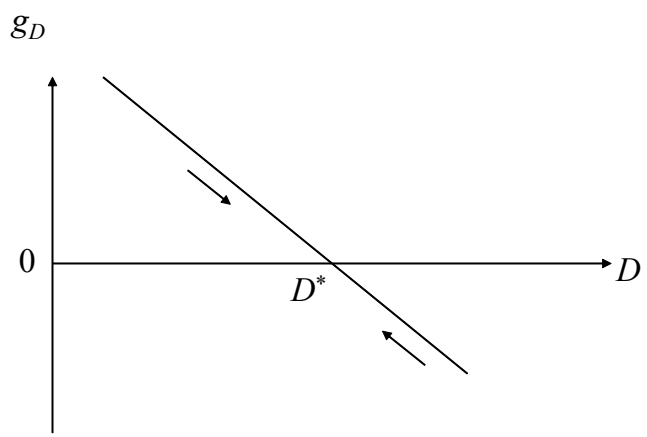

In the unstable case the phase line is positively sloped. Increased debt causes rising interest payments that exceed induced tax revenues, causing the budget deficit and the debt to explode.

If the initial level of debt is low, the economy may still be stable even if the interest rate condition is not satisfied so that $B_{D}>0$. Even though the interest rate is high, because the debt level is low the budget deficit contributes sufficiently strongly to aggregate demand that induced tax revenues outweigh the additional interest payments. The worst combination is therefore a high interest rate and a high level of debt. 
Finally, the significance of the interest rate for debt stability explains why the debate over the effect of the debt stock on the interest rate is so significant. If interest rates rise with debt, that is likely to increase the likelihood of instability. That is because the magnitude of the term $B_{D}$ in the stability condition will increase with $D$.

The analytics of the financially constrained case are slightly different. Recall, the solution for $Y$ given by equation (21) was

$$
Y=\left\{I+\left[\alpha-\alpha t_{\Pi}+t_{\Pi}\right] i D / p+[\gamma-i] D / p\right\} /\left\{1-\left[\beta-\beta t_{W}+t_{W}\right] \theta-\left[\alpha-\alpha t_{\Pi}+t_{\Pi}\right][1-\theta]-\psi\right\} .
$$

Differentiating equation with respect to $D$ yields

$d Y / d D=\left\{\left[\alpha-\alpha t_{\Pi}+t_{\Pi}\right] i / p+[\gamma-i] / p\right\} /\left\{1-\left[\beta-\beta t_{W}+t_{W}\right] \theta-\left[\alpha-\alpha t_{\Pi}+t_{\Pi}\right][1-\theta]-\psi\right\} \gtrless 0$.

If $d Y / d D>0$ this will help render the debt dynamics stabile and the economy will grow itself out of a debt trap through the positive aggregated demand effects of debt, operating via wealth and interest income. If $d Y / d D<0$ this will tend to render the debt dynamics unstable. There are two cases to consider. In case I the numerator is negative and the denominator positive. In case 2 the numerator is positive and the denominator is negative.

Regarding case $\mathrm{I}$, the numerator is negative if $i>\gamma /\left\{[1-\alpha]\left[1-t_{\Pi}\right]\right.$. Too high an interest rate causes instability. That is because higher debt increases interest payments that increase the deficit, forcing further cuts in government spending for which the negative aggregate demand effects outweigh the positive aggregate demand effects of higher interest income and debt wealth.

Regarding case 2 , the denominator is negative if $\left\{1-\left[\beta-\beta t_{W}+t_{W}\right] \theta-\left[\alpha-\alpha t_{\Pi}+t_{\Pi}\right]\right.$ $[1-\theta]-\psi\}<0$. This is the case of multiplier instability. Binding budget deficit caps make the budget automatically pro-cyclical and thereby introduce potential multiplier instability. If the deficit cap is binding and output and tax revenues fall, government spending must fall to satisfy the deficit cap, thereby amplifying the downturn.

Figure 5 illustrates the dynamics of instability. As output contracts, the absolute budget deficit shrinks but it remains a constant proportion of output, and it means the public debt continues to increase. Consequently, the debt to GDP ratio also increases. In terms of the earlier Figure 3, a negative demand shock can trigger a sequence of events that has the economy sliding left along the budget deficit cap line as demand and output shrink. Such a spiral can be identified with current conditions in Ireland or Greece where governments are committed to cutting spending to satisfy imposed deficit targets. ${ }^{9}$

9 Since $G$ is bounded from below (mathematically at zero or socially at the minimum level needed to keep society functioning) this spiral must eventually end. At that stage, a new policy regime must come into being. This regime might abandon the deficit cap. Alternatively, it might shift to complying with the budget cap by tax increases that are less contractionary than spending cuts, thereby allowing the standard (Blinder/Solow 1974) positive debt-demand expansion dynamics to reassert themselves. 
Figure 5: The case of instability with financially constrained government

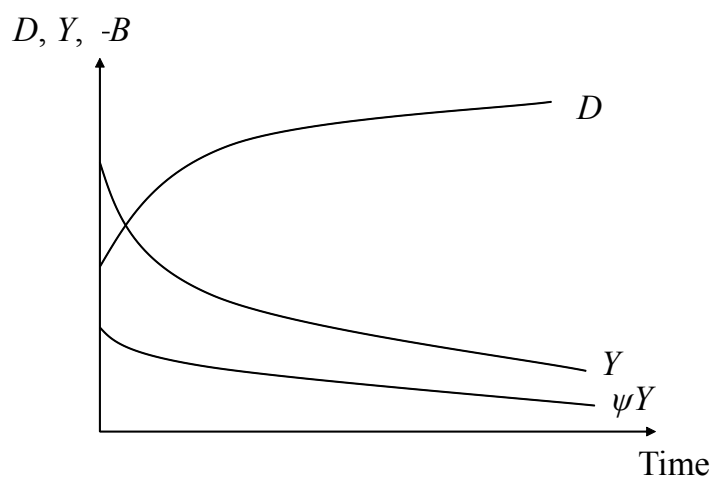

\section{Conclusion}

This paper has explored the macroeconomics of fiscal austerity and the effect of a lower price level in a simple Keynesian model with public debt. There are four key findings. First, imposing a binding budget deficit cap makes the economy more volatile by turning the government budget from an automatic stabilizer into an automatic destabilizer. Second, a large public debt helps maintain $A D$ in the presence of a lower price level, making public debt significantly different from private debt. In particular, a lower price level increases the real value of public interest payments which increases $A D$. Third, increases in public debt no longer automatically stabilize output if the economy is subject to a binding budget deficit cap. This is because the increase in real interest payments may be matched by spending cuts, giving rise to a negative balanced budget multiplier. Fourth, the combination of austerity via spending cuts plus budget deficit caps can produce instability. This last finding has explicit relevance to Ireland and Greece where the combination of imposed budget deficit caps and increased interest payments is driving a spiral of contracting government expenditure and income. 


\section{Appendix}

The proof of the inequality condition showing that a lower price level increases the budget deficit, assuming no wealth effect from public debt, is as follows. The deficit is given by

$$
B=T-G=t_{W} \theta Y+t_{\Pi}\{[1-\theta] Y-i D / p\}-i D / p-G .
$$

Differentiating with respect to $\mathrm{p}$ yields

$$
\begin{aligned}
& d B / d p=\delta T / \delta Y . \delta Y / \delta p+i D / p^{2} \\
& =-\left\{t_{W} \theta+t_{\Pi}[1-\theta]\right\} \alpha\left[1-t_{\Pi}\right] i D / m p^{2}+i D / p^{2}, \\
& m=\left\{1-\beta\left[1-t_{W}\right] \theta-\alpha\left[1-t_{\Pi}\right][1-\theta]\right\} .
\end{aligned}
$$

To show $d B / d p>0$ substitute for $\mathrm{m}$, simplify, and rearrange to yield the inequality

$$
\left\{1-\beta\left[1-t_{W}\right] \theta-\alpha\left[1-t_{\Pi}\right][1-\theta]\right\}>\left\{t_{W} \theta+t_{\Pi}[1-\theta]\right\} \alpha\left[1-t_{\Pi}\right] .
$$

The term $\alpha\left[1-t_{\Pi}\right]$ is less than one. Setting $\alpha\left[1-t_{\Pi}\right]$ equal to one increases the value of the left hand side, yet it can still be shown the inequality holds under this more stringent condition. Consequently, it must also hold when $\alpha\left[1-t_{\Pi}\right]<1$.

Set $\alpha\left[1-t_{\Pi}\right]=1$ and divide inequality (A.2) into two inequalities given by

$$
\begin{aligned}
& \theta-\beta\left[1-t_{W}\right] \theta>t_{W} \theta, \\
& \left.[1-\theta]-\alpha\left[1-t_{\Pi}\right][1-\theta]\right\}>t_{\Pi}[1-\theta] .
\end{aligned}
$$

It is then simple to show that inequality (A.3) holds if $1>t_{W}$ and inequality (A.4) holds if $1>t_{\Pi}$. Since (A.3) and (A.4) are satisfied by assumption, then (A.2) is also satisfied.

\section{References}

Blinder, A.S., Solow, R.M. (1974): Analytical foundations of fiscal policy, in: The Economics of Public Finance, Washington: Brookings Institution.

Caskey, J., Fazzari, S. (1987): Aggregate demand contractions with nominal wage commitments: Is wage flexibility stabilizing?, in: Economic Inquiry, 25, 583-597.

Fisher, I. (1933): The debt-deflation theory of great depressions, in: Econometrica, I, 337-357. Godley, W., Zezza, G. (2006): Debt and lending: A cri de coeur, Policy Note 4, The Levy Economics Institute of Bard College, Annandale-on-Hudson, New York.

Palley, T.I. (1994): Debt, aggregate demand, and the business cycle: An analysis in the spirit of Kaldor and Minsky, in: Journal of Post Keynesian Economics, I6 (Spring), 37I-390.

Palley, T.I. (1999): General disequilibrium analysis with inside debt, in: Journal of Macroeconomics, 2I, $785-804$.

Palley, T.I. (2008): The macroeconomics of aggregate demand and the price level, in: Investigacion Economica, LXVII, 263, 49-66. 
Palley, T.I. (20I0): The relative permanent income theory of consumption: A synthetic KeynesDuesenberry-Friedman model, in: Review of Political Economy, I, 4I-56.

Tobin, J. (1963): Deficit, deficit, who's got the deficit?, in: The New Republic, January 19. 
